\title{
RELATO DE EXPERIÊNCIA PARA APOIO A UM PERIÓDICO CIENTÍFICO
}

\author{
Gustavo Teodoro Bullé $e^{1}$ \\ Liane Mahlmann Kipper ${ }^{2}$ \\ Rosana de Cassia de S. Schneider ${ }^{3}$
}

No Brasil, o Sistema Eletrônico de Editoração de Revistas (SEER) foi disponibilizado pelo Instituto Brasileiro de Informação em Ciência e Tecnologia (IBICT, 2013) para agilizar o processo, reduzir custos e divulgar mundialmente as publicações científicas das instituições. O sistema é considerado por editores uma solução prática, econômica e eficiente, uma vez que promove a automação das atividades de editoração de periódicos científicos e permite completa autonomia dentro do fluxo editorial. Dessa forma, o editor pode definir as etapas do processo editorial de acordo com a política definida pela revista (MORENO, 2014).

O objetivo principal da equipe foi entender o Sistema Eletrônico de Editoração de Revistas (SEER) através do treinamento realizado, visando a aumentar a qualidade do periódico e buscar novos pesquisadores que submetam artigos, além de propiciar a divulgação da revista para todo o Brasil. O fato das revistas editadas em publicações eletrônicas serem acessadas e copiadas em qualquer lugar universaliza a cultura e diminui a restrição de espaço e de custos de acesso à informação científica, gerando mais cultura e maior intercâmbio global de conhecimento (BERGAMASCHI et al., 2012).

Durante a capacitação da equipe, realizada em 2013, foi focado no processo para a publicação de um periódico: submissão e recepção dos artigos, encaminhamento aos revisores, devolução aos autores para as reformulações necessárias, envio para correções ortográficas e publicação por meio eletrônico. Após a qualificação, realizou-se todo a de editoração e publicação das edições da Revista Tecno-Lógica, seguindo a ferramenta, desde a recepção dos artigos até a sua publicação, auxiliando o Editor e Editor Gerente da Revista.

Outra estratégia utilizada pelos editores para melhorar a qualificação do periódico, foi a elaboração de uma lista de endereços eletrônicos de pesquisadores, professores e alunos de diferentes universidades de todo o Brasil, convidando-os a submeter artigos e conhecer a Revista. Esta pesquisa ocorreu junto aos anais dos principais eventos das áreas de engenharia

\footnotetext{
${ }^{1}$ Bolsista do periódico Tecno Lógica e aluno do curso de Engenharia Civil da Universidade de Santa Cruz do Sul - UNISC. <gustavo@construfacilrs.com.br>

${ }^{2}$ Doutora em Engenharia. Docente do Programa de Pós-Graduação em Sistemas e Processos Industriais da Universidade de Santa Cruz do Sul Brasil - UNISC. <liane@ unisc.br>

${ }^{3}$ Doutora em Química. Docente do Departamento de Química e Física da Universidade de Santa Cruz do Sul UNISC.<rosana@unisc.br>
} 
de produção e tecnologia ambiental. As estatísticas e relatórios obtidos até o momento compõem os resultados do acompanhamento em relação ao incremento do número de submissões e publicações nesta revista. Nas Figuras 1 e 2 encontram-se dados que demonstram um incremento no total de submissões e de visibilidade da revista nos dois últimos anos.

Figura 1 - Submissões e publicações na Revista Tecno-Lógica em 2012-2013

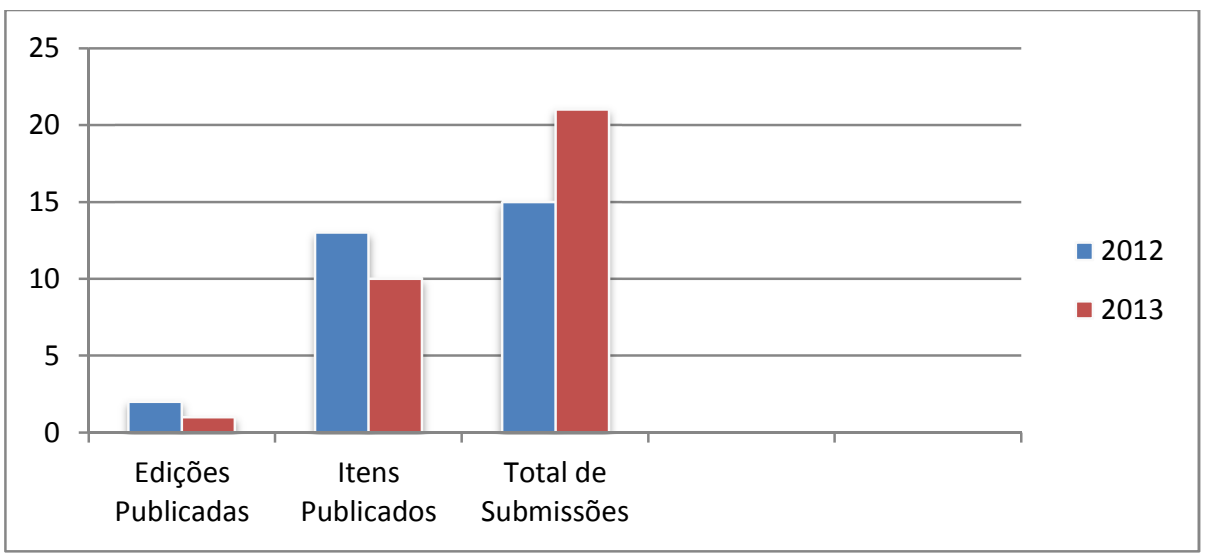

Figura 2 - Número de usuários da Revista Tecno-Lógica em 2012-2013

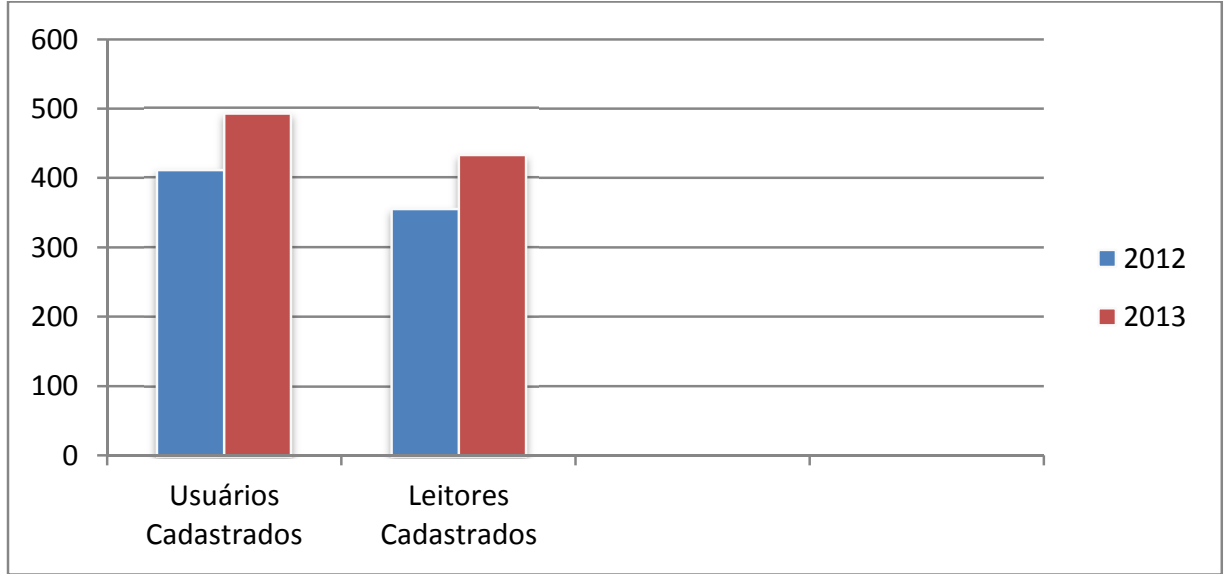

Estes resultados iniciais demonstram que a existência de uma equipe de apoio a um periódico científico é de vital importância para seu desenvolvimento. Os reflexos positivos decorrentes das ações realizadas em 2013 terão continuidade em 2014, buscando ampliar a visibilidade da Tecno-Lógica.

Destaca-se também que no último ano houve aumento de artigos recebidos comparado ao ano de 2012. 
Os temas diversificados das publicações, a qualidade das publicações e o número de artigos publicados, bem como a acessibilidade proporcionada com o uso do SEER, permitiram que no último ano, a Tecno-Lógica apresentasse um avanço no processo de divulgação científica de qualidade.

\section{REFERÊNCIAS}

BERGAMASCHI, R. J. P.; DUARTE, R. B. R.; O SEER e o processo de editoração de revistas científicas brasileiras. IX ENCONTRO VIRTUAL DE DOCUMENTAÇÃO EM SOFTWARE LIVRE E VI CONGRESSO INTERNACIONAL DE LINGUAGEM E TECNOLOGIA ONLINE. Anais... v. 1, n. 1, p. 1-7, 2012, Disponível em: http://www.periodicos.letras.ufmg.br/index.php/anais_linguagem_tecnologia/issue/view/121. Acesso em: 10 de mar. de 2014.

IBICT-INSTITUTO BRASILEIRO DE INFORMAÇÃO CIÊNCIA E TECNOLOGIA. Sistema Eletrônico de Editoração de Revistas. Disponível em: http://seer.ibict.br/index.php. Acesso em: 10 de mar. de 2014.

MORENO, F. SEER: Sistema Eletrônico de Editoração de Revistas: treinamento SEER Centro-Oeste. Disponível em: <http://www.ibict.br/anexos_secoes/seer.teorica.2006-2211.ppt>. Acesso em: 10 de mar. de 2014. 